\title{
Different Management Approaches in Impacted Maxillary Canines: An Overview on Current Trends and Literature
}

\author{
Iman Izadikhah' ${ }^{1}$, Dan $\mathrm{Cao}^{2}$, Zhenqi Zhao ${ }^{3}$, Bin $\mathrm{Yan}^{4}$
}

\begin{abstract}
Aim: This study aimed to overview and collect the current trends and techniques in managing maxillary impacted canines by retrieving recent literature, in a chronological manner from the prevention to the very late stages of treatment in adults.

Background: We performed a review on the recent literature regarding the current trends on the management of impacted canines. We have researched various types of available articles such as clinical trials and case presentations, meta- and systematic analyses, and literature reviews focusing on clinical management of impacted canines and their outcome evaluations. We adhered to those articles published within the last decade with a focus on treatment planning for impacted and displaced canines.

Review results: Depending on the diagnosis and its timing of it, a maxillary impacted canine can be managed by either prevention or interception, surgical opening followed by autonomous eruption or orthodontically traction, autotransplantation, and at last by removal and space closure. These techniques are elaborated one by one according to the age and severity of the diagnosis.

Conclusion: Impaction of the canines is a manageable abnormality which is highly dependent on the timing and localization of the displaced tooth. Early detection will give the upper hand to orthodontists to engage by either prevention through extraction of deciduous canines or intercepting via assistant devices to create more space. According to the clinical situation, open or closed surgical uncovering might be required to bond an attachment. However, generally, those techniques did not show any significant clinical distinction in the outcome assessments.

Clinical significance: These approaches are highly technique sensitive and require collaborations with other specialties. Proper diagnosis and prognosis assessment are necessary before making any decision to bring an impacted canine in alignment.

Keywords: Canine impaction, Maxillary canine, Orthodontic treatment, Prevention, Surgical techniques.

The Journal of Contemporary Dental Practice (2020): 10.5005/jp-journals-10024-2788
\end{abstract}

\section{BACKGROUND}

Impacted maxillary canines (IMCs) have always emboldened concernments among specialists and scholars. The level of attentiveness in the well-peer reviewed orthodontics journals along with the lack of recent literature reviewal materials exhilarated authors of this study to conduct an overview about available methods to treat IMCs.

In pathologic terms, tooth impaction can be defined as a state when a tooth remains embedded in the oral mucosa or intraosseous structures past its normal eruption period. However, the clinical definition of impacted teeth can be broadened to include teeth that are predicted to undergo an abnormal eruption process or teeth that are inducing resorption in the adjacent teeth roots, even before the normal eruption period. ${ }^{1}$ Maxillary canine impaction occurs 2 to 3 times more often in girls than boys. In general, palatal impaction of maxillary canines occurs 3 to 6 times more often than buccal impaction. Most maxillary canine impactions diverge from the normal eruptive site in either the buccal or the palatal direction (Fig. 1). ${ }^{1-4}$

A long pathway of eruption within maxillary apparatus and bony structures has made upper cuspids prone to be disturbed during their normal emerging time at 11 to 12 years of old. Alterations in the immediate environment of the unerupted maxillary canine by hard tissue bodies, soft tissue lesions, or developmental pathologic entities can cause the tooth to become impacted. Briefly, labial displacement or impaction of canines has been linked to spatial problems and arch width deficiencies. In case of palatal ones, they are theorized to be impacted by the rule of guidance and genetic theories. ${ }^{1,2,5,6}$
${ }^{1-4}$ Jiangsu Key Laboratory of Oral Diseases, Nanjing Medical University,
Nanjing, China; Department of Orthodontics, Affiliated Hospital of Stomatology, Nanjing Medical University, Nanjing, China

Corresponding Author: Bin Yan, Jiangsu Key Laboratory of Oral Diseases, Nanjing Medical University, Nanjing, China; Department of Orthodontics, Affiliated Hospital of Stomatology, Nanjing Medical University, Nanjing, China, Phone: +86 025 85031982, e-mail: byan@ njmu.edu.cn

How to cite this article: Izadikhah I, Cao D, Zhao Z, et al. Different Management Approaches in Impacted Maxillary Canines: An Overview on Current Trends and Literature. J Contemp Dent Pract 2020;21(3): 326-336.

Source of support: This study was supported by National Natural Science Foundation of China (81571005), Key R and D program of Jiangsu province (BE2018723) and the Priority Academic Program Development of Jiangsu Higher Education Institutions (PAPD, 2018-87).

Conflict of interest: None

Traditionally, the management of ectopic and unerupted teeth centers on the orthodontists, allowing a range of options including interceptive approaches, space recreation, autotransplantation, and orthodontic mechanical eruption to be considered (Fig. 2). ${ }^{7}$ It is unavoidable that an inaccurate three-dimensional diagnosis of location and orientation of impacted teeth and failure to appreciate anchorage demands can put a treatment procedure at risk of failure ${ }^{8}$ and patient dissatisfaction which advocated us to esteem the significance of an updated compendium.

() The Author(s). 2020 Open Access This article is distributed under the terms of the Creative Commons Attribution 4.0 International License (https://creativecommons. org/licenses/by-nc/4.0/), which permits unrestricted use, distribution, and non-commercial reproduction in any medium, provided you give appropriate credit to the original author(s) and the source, provide a link to the Creative Commons license, and indicate if changes were made. The Creative Commons Public Domain Dedication waiver (http://creativecommons.org/publicdomain/zero/1.0/) applies to the data made available in this article, unless otherwise stated. 


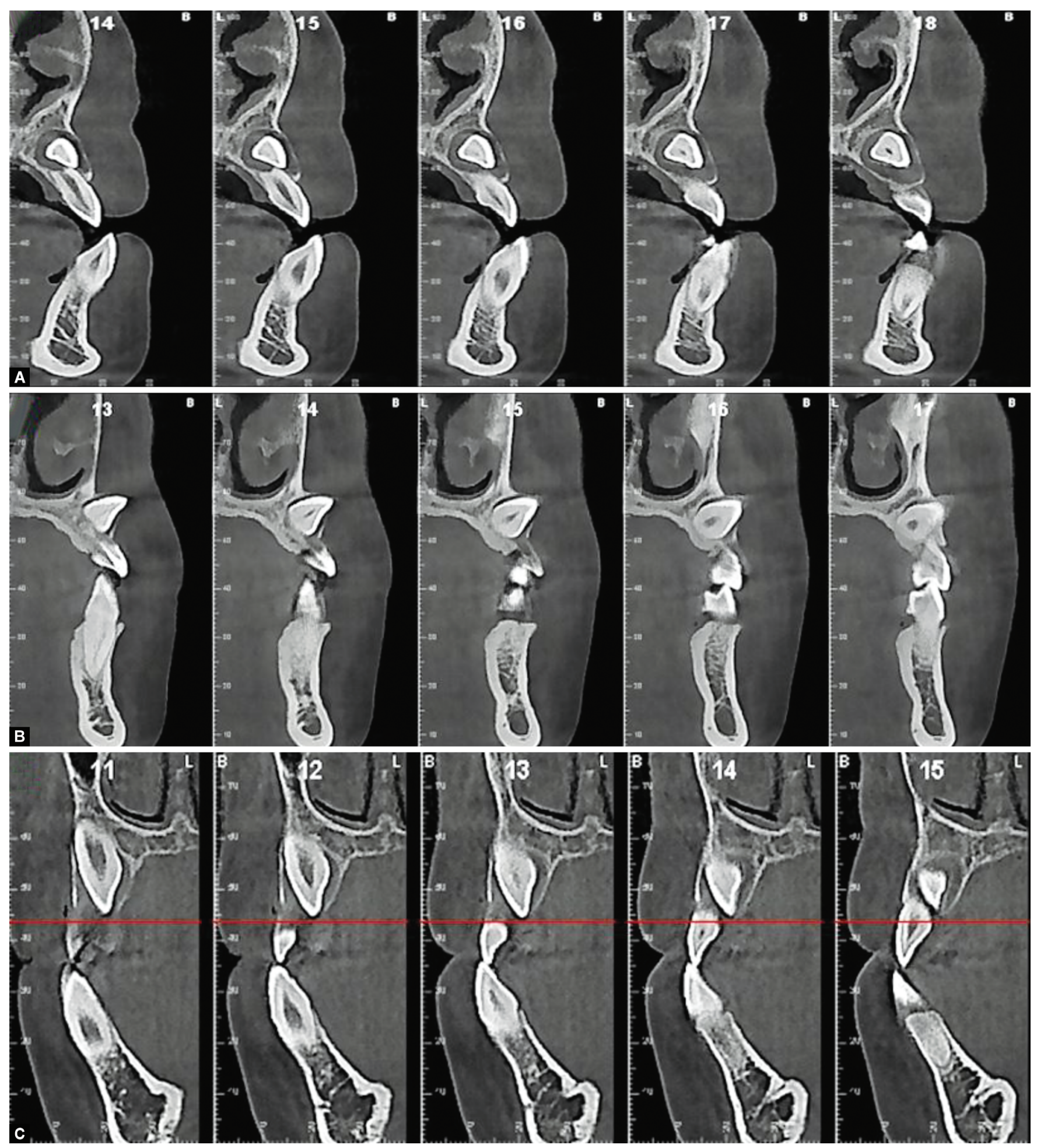

Figs 1 A to C: Different localizations of impacted canines in multi-slice reconstruction of CBCT: (A) Buccal; (B) Midalveolar impaction; (C) Palatally impacted (C)

This study aimed to overview and collect the current trends and techniques in managing maxillary impacted teeth by retrieving recent literature, in a chronological manner from the prevention to the very late stages of treatment in adults. To retrieve enough knowledge about this topic, recent published articles and clinical guidelines have been attained via online databases such as PubMed, Web of Science, and Embase. Selection criteria for articles were first relevancy of the paper to the science of maxillary impaction canine management and also the citation rate of the article. The terms included in the search were "Impacted canines," "maxillary impacted canines management," "treatment modalities in maxillary impacted canines," "management and/or treatment of displaced maxillary canines," and "management and/or treatment of ectopic maxillary canines." Papers with available full text in the form of 
- Early predicted cases

- Absence of resorption or cysts

- Absence of any mechanica obstruction

- Achieved by extraction of primary canines

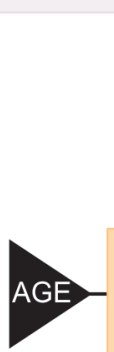

- Removal of obstructions such as supernumerary Teeth or odontomas - Opportunity for a preliminary luxation in case of ankylotic impacted canines
- Late patient referrals

- Significant displacement toward the lateral incisors

- Outcome will be Imperiled by patient age, horizontal angle of the impacted canine and proximity to the adjacent root apices
- When no other treatment plan is feasible

- Deeply dilacerated teeth - Severely dllacerated, closed apex, and ankylotic teeth - Followed by either space closure or implant restoration

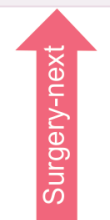

Autonomous eruption can be expected in cases with no dilaceration, open root apex; having adequate eruption space in late mixed dentition (10-13 years old)

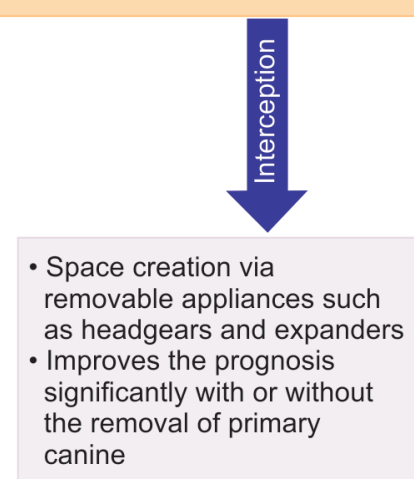

- Applicable to growing patients - Creation of space over-sufficiently - Force direction generally must be buccal and occlusal

- Occlusal and posterior force direction is required if the impacted tooth is close to lateral incisor

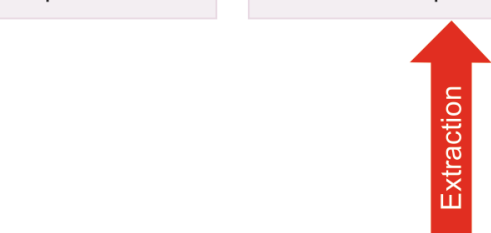

Late stages of root development They can be indicated due to lack of patient motivation to seek long time treatment

Fig. 2: A diagrammatic presentation of possible approaches in the management of impacted maxillary canines. Each colored arrow indicates the method along with its highlight points. The middle black arrow indicates the age progress. The middle yellow boxes are common considerations regarding the linked methods in each specific age range

Table 1: Factors assisting the prediction of impacted maxillary canines' occurrence

\begin{tabular}{|c|c|c|c|}
\hline Study & Predictive parameters & Utilized modality & Prediction power \\
\hline \multirow[t]{2}{*}{ Warford et al. ${ }^{10}$} & Cusp tip of the unerupted canine & Panoramic radiograph & Not absolute \\
\hline & $\begin{array}{l}\text { Overlapping level of canine to the midline of the } \\
\text { lateral incisor }\end{array}$ & & \\
\hline \multirow[t]{3}{*}{ Alqerban et al. ${ }^{11}$} & The canine angulation to the lateral incisor & $\mathrm{CBCT}$ & Significantly strong \\
\hline & The canine cusp tip to the occlusal plane & & \\
\hline & The canine crown position & & \\
\hline \multirow[t]{3}{*}{ Alqerban et al. ${ }^{9}$} & Canine to first premolar angle & Panoramic radiograph & Weaker than $\mathrm{CBCT}$ \\
\hline & Canine cusp to midline distance & & \\
\hline & Canine cusp to maxillary plane distance & & \\
\hline
\end{tabular}

clinical trials, case reports, clinical guidelines, and systematic and metanalytic reviews were scrutinized by two different reviewers.

\section{Review Results}

\section{Preventive and Interceptive Approach}

As a first step to prevent occurrence of canine impaction, practitioners must be able to predict happening of such anomaly (Table 1). In a retrospective manner, Alqerban et al. reported that the three best parameters to distinguish between impacted and nonimpacted canines were canine to first premolar angle, canine cusp to midline distance, and canine cusp to maxillary plane distance. ${ }^{9}$ Prior to that, Warford et al. ${ }^{10}$ also suggested that the location of the cusp tip of the unerupted canine is the most important predictor of eventual impaction. They found that angulation assessments did not increase the prediction of eventual impaction, but the more mesial the cusp tip location, the greater the likelihood of impaction. Moreover, Alqerban et al. in the latter study graded the ability of oral panoramic radiograph "weak" in the prediction of ectopic canines, while in another study, they rated cone-beam computed tomography (CBCT) as an excellent modality in the canine impaction prediction. ${ }^{11}$ Despite a limited sample size, they concluded that canine angulation to the lateral incisor on the coronal view, the canine cusp tip to the occlusal plane on the sagittal view, and the canine crown position were the strongest predictors based on the $\mathrm{CBCT} .^{11}$

Aside from radiological modalities, other clinical assessments such as arch dimensional evaluation and physical palpation of the prone-to-be area of impacted canine can help to localize the abnormality. In a retrospective study, Sajnani has also emphasized on the necessity of determining the position and angulation of the impacted canines on treatment planning. ${ }^{12}$ Practically, the magnitude of required vertical movement and the approximation to 
adjacent roots should also be evaluated. According to his findings, buccally mal-positioned canines would require to provide both distal and occlusal movement. To bring the tooth to an acceptable angulation, the apex may need to be moved in a distal direction. ${ }^{12}$

Better clinical assessments would help practitioners to make the best decision either to monitor or to intercept. Doğramacı and Naini have concluded that under limited circumstances, early prediction of impacted canine might not need any interception. Apart from patient motivational conditions to pursue orthodontics treatment, the absence of resorption or any mobility coming from a cystic activity can guide us to observe more. ${ }^{13}$ However, the complexity of the malocclusion might be in a way that achieving proper alignment is unattainable at the time and requires more monitoring. ${ }^{13}$

History of deciduous canines' extraction as a method of preventing occurrence of canine impaction goes back to decades ago. Retention of deciduous canines and their persistence against on-time exfoliation is the very basic recognition criteria for physical obstruction of a permanent canine emergence into oral cavity. Therefore, in the late mixed dentition, the primary canine can be extracted to prevent the impaction of permanent canine as an interceptive treatment. ${ }^{2}$ However, like every other clinical procedure, this also requires a cautious case selection. Factors such as age, sex, site of the potential impacted tooth, and absence of crowding play an important role. ${ }^{13}$ The age of $10-13$ years has been already established to be the best age to intercept by removing primary canines. ${ }^{13,14}$ In cases of no improvement within a year or lack of enough space, additional treatments are recommended. ${ }^{14}$ Extraction of primary canines has advantages such as technique simplicity and cost-effectiveness, ${ }^{7,14}$ but it is still counted as a controversial approach with different reported success rates. ${ }^{15-17}$

The very initial reported success rate for this method is $78 \%$ and belongs to Ericson and Kurol based on a prospective study over a 12-month period. ${ }^{18}$ However, their rate was declined to $64 \%$ when the canine was medially displaced beyond the midline of the adjacent lateral incisor. ${ }^{18,19}$ Sajnani and King performed a retrospective audit on 448 case histories and reported only $47.4 \%$ of success rate. ${ }^{20}$ This rate is consistent with what Leonardi et al. proposed (50\%) before them. ${ }^{21}$ All these rates are significantly dependent on previously mentioned factors such as positioning and angulation of the tooth and also different evaluation methods. For example, the success rate would significantly drop if the impacted crown is positioned mesial to the midline of the adjacent incisor and angulation of the long canine axis in relation to the midsagittal plane exceeds $31 .{ }^{22}$ Nevertheless, the most important contributing factor in prognosis was reported to be the horizontal overlap of the incisor nearest to the displaced canine. ${ }^{23}$

\section{Assisted Interception with Other Devices}

In a systematic analysis, Naoumova et al. could not establish any evidence-based conclusion about effectivity of primary canine extraction. ${ }^{24}$ Their study also aimed to discover the effectivity of using primary canine extraction as an isolated treatment plan vs using other modalities adjunctively to that. Even though they failed to answer that, Alyammahi et al. in their systematic review confirmed the usefulness of space maintaining after the extraction. ${ }^{15}$ Generally, the success rate of primary canine removal has been reported to be significantly higher when it is supplemented with space creational methods such as face masks, cervical or straight pull headgears, rapid maxillary expansion, or removal of multiple deciduous teeth alternatively or adjunctively (Fig. 3). ${ }^{7,25-27}$ As for cervical pull headgears, the nighttime treatment with a headgear aside from the extraction has elevated successful eruption up to $87.5 \%$ of the cases. ${ }^{26,28}$ According to Baccetti et al.'s experiment, subjects who did not receive headgears showed a significant mesial movement of their upper first molars. ${ }^{26}$ Therefore, the principal effect achieved via headgears is a preventive role in the mesial movement of the posterior segments of the upper arch, ultimately providing an eruption pathway for the impacted tooth. ${ }^{26} \mathrm{~A}$ maxillary expansion protocol also possibly facilitates the eruption of canines by improving the intraosseous position of the impacted teeth. ${ }^{2}$

Armi et al. in a randomized clinical trial decided to exclude extraction of primary canines from the treatment options. They
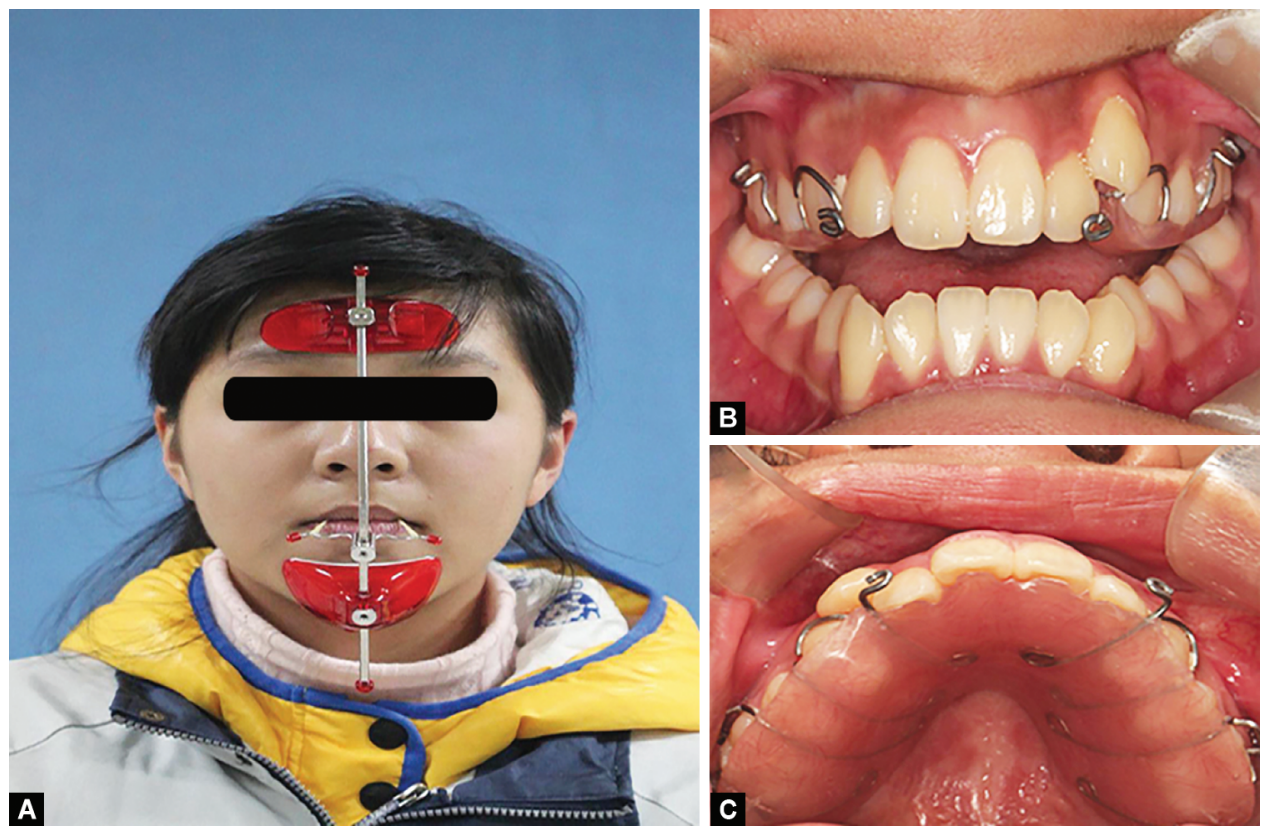

Figs $3 \mathrm{~A}$ to $\mathrm{C}$ : Interceptive approach assisted by a facemask to create additional space in maxillary arch as visualized in: (A) Extraoral frontal view; (B) Intraoral frontal view; (C) Occlusal view of the maxillary arch (C) 
grouped their samples into three which were cervical pull headgear group, rapid maxillary expansion/headgear group, and the control group. ${ }^{25}$ They found out even without the extraction of primary canines, orthodontic treatment supplemented with rapid maxillary expansion and/or cervical pull headgear can significantly enhance the rate of successful eruption of the permanent canine up to three times. ${ }^{25}$ From the clinical point of view, the findings by Armi et al. are implying that preserving upper arch perimetersparticularly anterior maxillary dimension-is important as removal of deciduous teeth which are acting as a mechanical obstacle. ${ }^{28}$ Recently, Hadler-Olsen et al. had a randomized trial to assess the correlation between the arch size discrepancy and the effectivity of headgears in class II patients. ${ }^{29}$ Interestingly, they reported aside from the influence that headgears have on eruption path, they are significantly improving patients by expanding the arch. They stated that maxillary expansion resulting from headgear treatment was larger in narrow arches compared with broad dental arches. Additionally, they postulated that due to a relief effect of the inner headgear bow against the pressure of the lip musculature, a "lip bumper effect" was provided which ultimately resulted in an significant increase in inter-canine distance. ${ }^{29}$ This guided the authors of that study to state that the anterior part of the maxilla appears to be the most important factor in how much the maxillary canine erupts vertically.

\section{Surgical Approach}

In case that interceptive procedures become ineffectual for whatsoever reason, the next preference would be a combination of surgical and orthodontic procedures to bring the impacted tooth in normal alignment. ${ }^{7,30}$ Mostly, this occurs due to late referrals of patients when the displaced crown is significantly toward the mesial and past the root of adjacent lateral incisors. Especially in cases of palatal displacements, surgical exposure of the canine is necessarily followed by orthodontic movement of the tooth into the dental arch. After surgical uncovering, we can either aim for autonomous eruption or passive eruption by orthodontic forces according to the clinical evaluations. ${ }^{31}$

\section{Timing in Surgical Involvement}

According to two different studies done by Becker and Chaushu ${ }^{30}$ and Becker et al., ${ }^{32}$ the timing of the surgical involvement has been discussed from two standpoints. Primarily, a "surgery first" approach was explained to be beneficial for achieving several goals. As such, we can aim for autonomous natural eruption, simplifying the orthodontic treatment by minimizing the delay, removal of supernumerary tooth or odontome in case of physical obstructions, and finally providing access to the tooth for the later placement of an attachment and for the application of traction. ${ }^{30}$ As mentioned in another study, what standard procedure precepts is orthodontic alignment and leveling of the teeth in the dentition as the initial goal, followed by the space creation to accommodate the impacted tooth in the arch. ${ }^{32}$ Alignment should be followed until a rectangular stainless steel wire can be placed to avoid the adverse effects of traction such as intrusion of adjacent teeth, constriction of dental arch, or change on occlusal plane. ${ }^{22,33}$ Next would be attaining anchorage from all the teeth by consolidation and stabilizing the teeth in that jaw by placing a full thickness passive arch-wire in all the brackets. This anchorage unit can be further supported by other elements such as intermaxillary elastic forces, extraoral forces, and temporary anchorage devices (TADs) if needed. Then, it is the time for surgical approach to uncover the tooth. ${ }^{32}$
There are cases that relying on surgery as the sole option of treatment would not be clinically reasonable. These conditions are inadequate space which might impede the natural eruption, low chance of autonomous eruption, possible irreversible damage to the periodontium or the cementum layer of the root, impossible immediate application of orthodontic traction, signs of resorption in adjacent laterals, and at last when the tooth is impacted deeply. $8,30,34$

\section{Influential Factors in Decision Making}

As proposed by Vanarsdall, buccal-impacted canines are counted to be more difficult in controlling the adverse periodontal outcomes during management, and they require special attention in invasion level of surgical techniques, placement of marginal gingival with proper gingival attachment, inflammation control, and avoidance of uncontrolled or excessive force. ${ }^{35}$ However, it is believed that surgical exposure and orthodontic alignment of a palatally impacted canine can be a highly successful treatment approach. ${ }^{14}$

In some cases, before making the final decision, the choice of premolar extraction in each quadrant might be posed as an adjunct way to provide space. However, if the choice is between an aligned healthy premolar and a deeply impacted canine with a questionable periodontal outcome, it is the canine that rather should be extracted. ${ }^{36}$ Gingival inflammation has been described as another important factor in surgically assisted traction of impacted canines especially in the forms of gingival recession, loss of alveolar bone, or attached gingiva. ${ }^{37,38}$ Site and angulation of the impacted canines is believed to have no impact on their periodontal outcome. ${ }^{37,39}$

Doğramacı and Naini have enumerated some indicative factors prior to treatment planning. First, a favorable position of the impacted crown in both the anteroposterior and vertical planes for alignment according to radiographic assessments followed by 8 to $9 \mathrm{~mm}$ of available space (which could be made) for accommodation of the ectopic tooth. ${ }^{13}$ Obviously, the displacement level should not make the orthodontic alignment impractical (e.g., close proximity to the midline, above the apices of the adjacent teeth, and horizontal angulation). ${ }^{14}$ The displacement level can directly influence the time span of the treatment and complexity of the surgical process. There might even be further complications by anatomical problems, such as position of the lateral incisor roots, orientation of the canine, and difficulty in accessing the displaced tooth. Ectopic buccal canines present a particular challenge in negotiating the root of the maxillary lateral incisor during alignment. ${ }^{7,40}$ By the help of regression analysis, Pitt et al. have concluded that determinant factors in difficulty of treatment are horizontal position, age of patient, vertical height, and bucco-palatal position, in descending order of importance. ${ }^{41}$ Age has a direct effect on the success rate of impacted canine treatment. ${ }^{42}$ For example, in cases with palatally displaced canines, the inability of the tooth to emerge in occlusion is considered to become more marked in adults., ${ }^{7,31}$

\section{Different Surgical Methods}

The preferred method for surgical approach is highly dependent on the location and level of displacement within the bone. ${ }^{43}$ According to Huang et al., the key factors toward making final decision are the amount of keratinized tissue in the area of the impacted tooth, the vertical position of the impaction relative to the mucogingival junction (MGJ), and the mesiodistal position of the canine crown. ${ }^{44}$ An apically positioned flap is more predictable to increase the keratinized tissue width if there is insufficient gingiva. When a patient has a highly impacted canine and the crown tip is 
Table 2: Possible surgical approaches to an impacted maxillary canine

\begin{tabular}{|c|c|c|c|}
\hline Surgical procedure & Indications & Descriptions & Disadvantages \\
\hline \multirow[t]{2}{*}{ Open exposure } & Coronal crown position to the MGJ & $\begin{array}{l}\text { More crown visualization permitting } \\
\text { accurate bond placement }\end{array}$ & $\begin{array}{l}\text { Longer recovery time in } \\
\text { buccal impaction chance of } \\
\text { keratinized tissue loss }\end{array}$ \\
\hline & Sufficient keratinized gingiva & & \\
\hline \multirow[t]{3}{*}{ Window technique } & $\begin{array}{l}\text { Palpable impactions above the level of } \\
\text { the attached gingiva }\end{array}$ & $\begin{array}{l}\text { Semilunar window for buccal } \\
\text { impactions }\end{array}$ & $\begin{array}{l}\text { Higher danger of gingival } \\
\text { overgrowth }\end{array}$ \\
\hline & & $\begin{array}{l}\text { For palatal impactions, } 5-7 \mathrm{~mm} \\
\text { incision thickness beneath the surface }\end{array}$ & Prone to infections \\
\hline & & & More painful \\
\hline \multirow[t]{2}{*}{ Flap procedures } & $\begin{array}{l}\text { Impactions above the level of the MGJ } \\
\text { and not displaced mesial or distal to the } \\
\text { normal position }\end{array}$ & Full flap for palatal impactions & $\begin{array}{l}\text { Chance of crown instability } \\
\text { and re-intrusion }\end{array}$ \\
\hline & & $\begin{array}{l}\text { Apical repositioned flap for labial } \\
\text { canines }\end{array}$ & \\
\hline \multirow[t]{2}{*}{ Closed exposure } & $\begin{array}{l}\text { Deep impacted cases. Buccal impactions } \\
\text { which are deviated from the normal }\end{array}$ & $\begin{array}{l}\text { A less aggressive method which the } \\
\text { surgical site will be resutured involves }\end{array}$ & $\begin{array}{l}\text { Harder to control orthodontic } \\
\text { force }\end{array}$ \\
\hline & position & $\begin{array}{l}\text { less vertical relapse and better esthetic } \\
\text { outcomes }\end{array}$ & $\begin{array}{l}\text { Bond failure due to } \\
\text { contamination }\end{array}$ \\
\hline \multirow[t]{2}{*}{ Tunnel technique } & Midalveolar impactions & A modification of closed surgery & $\begin{array}{l}\text { Necessary to have the } \\
\text { deciduous canine }\end{array}$ \\
\hline & & Helps in preservation of buccal plate & \\
\hline \multirow{2}{*}{$\begin{array}{l}\text { Corticotomy-assisted } \\
\text { exposure }\end{array}$} & Deep and ankylotic impactions & 2-4 times faster tooth movement & Highly aggressive \\
\hline & & $\begin{array}{l}\text { Significantly dependent on pretreat- } \\
\text { ment position in palatally impacted } \\
\text { canines }\end{array}$ & \\
\hline
\end{tabular}

properly aligned mesiodistally, a closed eruption technique can be considered. Once a maxillary canine is highly impacted and its crown protrudes labially or its cusp tip is displaced mesially, twostage approaches may be indicated in which exposure is carried out first and mucogingival surgery is performed at a later stage. ${ }^{44}$ To date, different authors have presented a variety of classifications and categories, but here is a summary of the most referred ones (Table 2).

Open surgical exposure. It is defined as surgical uncovering of the overlying mucosa and the alveolar bone. ${ }^{45}$ Where the canine is superficially positioned, open exposures allow visualization of the crown permitting accurate bond placement. ${ }^{7}$ In cases of the coronal crown to the MGJ and sufficient keratinized gingiva, a simple excision procedure will be adequate. ${ }^{44}$ This method can be divided into three other variants for different occasions: (1) window technique, (2) full flap open procedure, and (3) apically repositioned flap technique. ${ }^{30,32,46}$

Window technique. The simplest and the most direct form of exposing an impacted canine which is usually placed superficial and palpable above the level of the attached gingiva and covered only by a thin and mobile oral mucosa. In buccal-impacted canines which can be palpated above the level of the attached gingiva, a semilunar window will expose the tooth. But in palatally impacted canines, because of thick mucosa, bone, and follicle, they are 5 to $7 \mathrm{~mm}$ beneath the surface which demands a deeper and more challenging surgical removal of a circular area with riskier bonding process of attachments (Fig. 4A).$^{30-32}$ To prevent the growth of granulated tissue and control the pain, the use of surgical dressings such as Coe-Pak or a healing plate is recommended. ${ }^{13,30}$
Occasionally, in deeper impactions, a moderate luxation for the purpose of "loosening it up" or "to check if it is ankylosed" can help by provoking spontaneous eruption or redirecting the eruption path. However, it might induce cervical root resorption process or ankylotic union. ${ }^{30}$

Flap procedures. Flap procedures can be in the form of a full flap for palatal impactions. It is done by maximum exposure of the tooth and suturing the flap back to its former place, while a circular portion of the attached mucosa is excised. ${ }^{47}$

Another variation is apical repositioned flap for labial canines. This method is indicated if the canine is situated above the level of the MGJ and not displaced mesial or distal to the normal position in arch. ${ }^{30,32}$ Even though this technique can preserve the keratinized tissue, it is not applicable in deeply impacted cases. ${ }^{44}$ However, if the location of the impacted tooth is above the MGJ, this technique might cause crown instability and re-intrusion of the tooth after orthodontic treatment because of the stretches in the repositioned gingiva due to tooth movement, which lead to relapse after the treatment. ${ }^{48}$

Closed surgical exposure. A less aggressive method refers to elevating a mucoperiosteal flap, removing sufficient bone to expose the crown and permit tooth movement, bonding a chain, resuturing the flap, and leaving the chain exiting through the gingiva. ${ }^{31}$ Closed surgeries are indicated in deep impacted cases and also buccal impactions which are deviated either mesially or distally from the normal position. ${ }^{30,32}$ The closed eruption technique exhibits less vertical relapse and more esthetic results because of less gingival scarring. ${ }^{43}$ However, in this method, since the tooth is not any more visible, orthodontic force cannot be controlled during traction. ${ }^{44}$ 

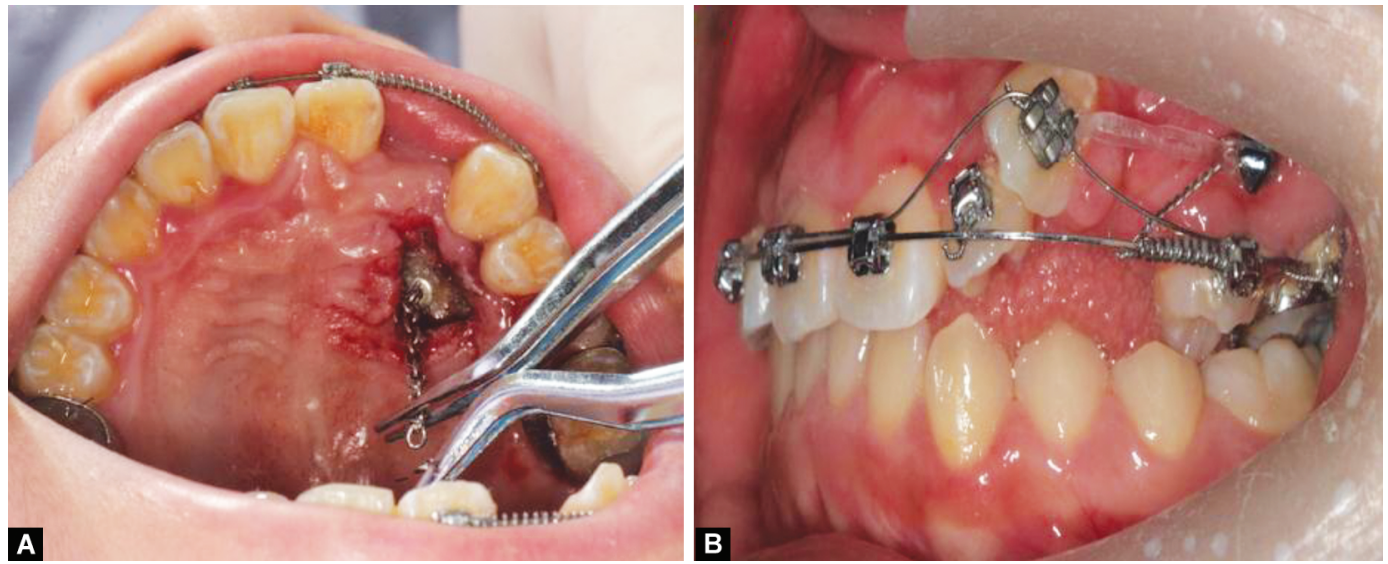

Figs $4 \mathrm{~A}$ and B: Traction of an impacted tooth after open surgical uncovering and bond attachment in a palatal canine (A) and also visualization of extra anchorage support by TAD supplemented by a double-arch-wire technique in disimpaction of a buccally impacted canine (B)

According to Becker and Chaushu, ${ }^{30}$ exposure can be done minimally with opening the follicle just sufficient for bonding an attachment, and leaving the rest of the follicular tissue intact. Or in a more fiercely attempt, exposure can be achieved via total enucleation of the entire follicle covering the tooth. ${ }^{32}$

Tunnel technique. Originally, it was introduced by Crescini et al. for impacted cases which are positioned highly midalveolar. ${ }^{49}$ It is recognized as a modification of closed surgery for preservation of buccal plate and avoiding an erupted tooth with a long, unesthetic crown, and reduced bone support on the labial side. ${ }^{30}$ It is done by traction of the impacted tooth downward through the socket of extracted deciduous canine. ${ }^{32}$

Corticotomy-assisted exposure. This technique was analyzed by Fischer in treatment planning for impacted canines. ${ }^{50}$ In a clinical trial, he compared bilateral palatal impactions, where one side was exposed by conventional methods, and their contralateral side was exposed by corticotomy. Ultimately, he obtained a faster tooth movement for all the cases with no significant difference in the periodontal outcome..$^{50}$ In a recent analysis by Ferguson et al. on 151 palatally impacted teeth, ${ }^{51}$ they found that this method around the impacted teeth will provide 2 to 4 times increase in the rate of tooth movement compared with closed exposure. ${ }^{51,52}$ It includes performing ostectomy between the adjacent teeth to provide a pathway from the impacted canine crown to the final archwire position but leaving about $1.5 \mathrm{~mm}$ of bone interproximally. Furthermore, it should be followed by penetrations over the root prominence of the impacted tooth toward movement direction. ${ }^{51}$

Outcome evaluations: open vs closed surgeries. In terms of periodontal health, Parkin et al. has concluded that these two techniques present no impact on the prognosis of the palatally impacted canines after the treatment. ${ }^{47}$ Their result was confirmed by Sampaziotis et al.'s systematic review. ${ }^{53}$ They also concluded that in palatal impactions, both methods have the similar amount of postoperative pain, with a slightly faster recovery in closed surgical approaches. Regarding buccal impactions, both closed and open exposures result in longer recovery time compared with palatal impactions. ${ }^{32}$ In a meta-analysis, Cassina et al. recently found that the open surgical approach presents a better result than the closed technique in terms of reduced initial alignment duration and decreased risk of ankylosis. ${ }^{54}$ Buccal impactions which are surgically exposed with the open technique will likely lose about 1 $\mathrm{mm}$ of keratinized tissue, when compared with normal physiological eruption. ${ }^{55}$ However, open and closed exposures specifically for buccally impacted canines have not yet been directly investigated, and there is a lack of sufficient literature. ${ }^{32,56}$ But generally from the esthetical point of view, it is concluded that open and closed exposures present no difference. ${ }^{57}$

\section{Autonomous Eruption after Surgical Uncovering}

After open surgical exposures in palatal impactions, this technique can be performed in early mixed dentition, and a physiological eruption is expected within the first 9 months. However, adults will experience a longer process time near 1 year. ${ }^{31}$ It is theorized that a thick gingival layer over the crown slows the natural eruption process and can lead to delayed eruption. In addition, because of the elastic fibers present in the gingival tissues, they are flexible and expandable. ${ }^{58}$ Even though bone loss might occur adjacent to the previously impacted tooth, generally autonomous eruption will result in esthetic, biologically sound, functional, and stable outcome. ${ }^{59,60}$

As described by Sherwood, the surgical technique is similar to the elevation of a flap in closed approach, but a fenestration or a window is made through the palatal gingiva over the superficially buried canine. ${ }^{58}$ The opened window should be sufficient enough to expose the maximum surface of the impacted crown to overcome the unavoidable regrowth of the gingiva. The flap is sutured back in place supported and covered by a surgical dress.

\section{Mechanical Traction of the Surgically Uncovered Impacted Teeth}

Orthodontic traction of the impacted canine is more indicated in growing patients, without severe arch space deficiencies. ${ }^{61}$ As declared by Sajnani, orthodontically alignment of an impacted canine in maxillary arch must be followed by three stages. ${ }^{20}$ The first stage is creation of sufficient space and even slightly more since the canine is unlikely to be at its ideal angulation, and the crown will, therefore, occupy additional space. An important point to remember here is, if premolar extraction is selected as an option to create the space, it should be done after the assurance of impacted canine mobility or else the ankylosed impacted tooth is indicated for extraction. ${ }^{4}$

The second stage deals with the correct direction of movements toward the arch. Generally, the movement of the crown must 
be in a buccal and occlusal direction into the optimum location in the arch. ${ }^{20}$ However, if the canine is in close proximity to the incisor roots, a buccally directed force may cause damage and no movement would be achieved due to the root obstacle. Therefore, an occlusal and posterior direction is required primarily and then moving it buccally into the desired position. ${ }^{4}$

The final stage deals with the angulation, apical and vertical position, and rotation. A buccally placed canine may require a significant amount of both distal and occlusal movements with more focus on distal to protect adjacent root structures. Moving the apex in a distal direction can provide a clinical acceptable angulation. ${ }^{20}$ In terms of angulations and tipping, if the apex is in the line of the arch in the buccolingual plane and in the mesiodistal plane, then the crown of the tooth will only need to be tipped into its place in the arch, a relatively simple biomechanical exercise. ${ }^{30}$

In addition to bonding of conventional golden chains and heavy rectangular arch-wires, there are other auxiliary mechanics in traction of an impacted canine into the arch. The conventional alignment can put the adjacent laterals in risk of resorption due to expressed torque from wire and leading the incisor apex in closer approximation to the resorptive follicle of the impacted canine. ${ }^{62}$ Aside from that in cases of ankylosed impacted teeth, supplementary anchorage can be obtained via TADs. ${ }^{63}$ Temporary anchorage devices allow a more controlled movement of the impacted tooth, and this is important in the prevention of root resorptions before the disimpaction ${ }^{62}$ as a reliable and convenient skeletal anchorage (Fig. 4B). ${ }^{63}$ The main advantage of this method is that the maxillary arch may not be bracketed until canine is disimpacted, and ankylosis can be ruled out. ${ }^{62,63}$ However, they also have side effects such as soft tissue irritation and a potential place for plaque accumulation and further gingival inflammations. ${ }^{63}$

Another current technique is Ballista spring usually constructed by a 0.014 -in. round Australian wire. This method has an added advantage over other methods that it could be used before and during leveling and alignment phase. ${ }^{64}$

Additional traction technique accompanied by a surgical exposure uses cantilever on the segmented arch technique. ${ }^{65}$ Segmented arch technique consists in the dental arch segmentation for the consolidation of teeth in active units and a passive unit (anchor), designed by Charles Burstone in 1962. This technique can be applied to the cantilever, which is a device used for dental traction, being made from titanium and molybdenum alloy wire. ${ }^{65}$ In a case report by Nakandakari et al., ${ }^{65}$ this method has reported to have an efficient and predictable outcome, because it is of statically determined mechanics.

In 2008, Schubert treated 103 patients by a method called EasyWay-Coil ${ }^{\varpi}$ system in an average treatment time of 17.8 months from surgical exposure to removal of the fixed appliance. ${ }^{66}$ Although this technique was reliable, efficient, easy to use, and economical, it will not be indicated for ankylosed impactions. However, recently, it has been proven to be helpful in multiple and simultaneous impactions of maxillary canines and premolars. ${ }^{67}$ Finally, other techniques such as K-9 springs and double-arch-wire mechanism also have been reported to be useful in pulling out in impacted canine (Fig. 4B). ${ }^{68,69}$

\section{Transplantation}

It is defined as surgical removal of a tooth in an individual, and its placement in another desired place in the arch of the same individual. ${ }^{14}$ Although not routinely, autotransplanting can be a helpful treatment in cases of failure or impracticality of previously discussed methods or patient unwillingness to pursue orthodontic treatment. ${ }^{14,70}$ As an alternative to removal of an impacted canine, this method is indicated where there is high positioning or an angulation larger than $45^{\circ}$ relative to the occlusal plane. ${ }^{71}$ Compared with restoration with implants, transplanted teeth have advantages such as functional adaptation and preservation of the alveolar ridge and also might recover its proprioceptive function and normal periodontal support. $^{72}$

Different fixation methods have been reported after the surgical removal from the original place. Methods such as suturing, orthodontic wire, plastic vacuform splint, and metal cap splint are stated to be useful, and the fixation will last between 2 weeks and 6 months. ${ }^{71}$ Depending on the apical foramen diameter and its closure status (root formation more than $75 \%{ }^{14}$ ), endodontic treatment of autotransplanted canines might be necessary. In cases of open apices, an observational and control strategy is accepted due to capability of an immature tooth to revascularize. ${ }^{71}$ However, open apex teeth have been reported to have a higher success rate compared with those closed apex. ${ }^{71,73}$

\section{Removal of the Impacted Canine}

Removal of an impacted tooth can be indicated when clinical assessment of the treatment feasibility leads practitioners to no choice but extraction of the displaced tooth. Considering the time consumption, invasion of surgical process, unpredictability of every possible treatment outcome, and finally patient uncooperativeness are reasons to consider this modality (Fig. 5). ${ }^{2,8,11}$ Space closure following the impacted teeth removal can be done by two ways. The first and simplest way is protracting the premolars in the canine position and reshaping them. If necessary, to mimic a canine morphology mesio-palatal rotation of the premolar and placement of buccal root torque can help to promote esthetics. ${ }^{14}$

Replacement of the single impacted tooth through a single implant is another reasonable treatment option that has been reported with an acceptable clinical outcome. ${ }^{74,75}$ Recently, Zuiderveld et al. concluded that under the premise of preservation of sufficient bone to achieve primary stability of the implant, immediate restoration and provisionalization of the implant can be done following the surgical removal of the impacted canine and providing adequate mesiodistal space. ${ }^{76}$ However, as confirmed by them, this option is not possible to apply in mixed dentition or the patient who has not completed the growth. ${ }^{76}$

\section{Conclusion}

Impaction of the canines is a manageable abnormality which is highly dependent on the timing and localization of the displaced tooth. Early detection will give the upper hand to orthodontists to engage by either prevention through extraction of deciduous canines or intercepting via assistant devices to create more space. Late diagnosis of impaction would require a collaboration with other specialists. According to the clinical situation, open or closed surgical uncovering might be required to bond an attachment. However, generally, those techniques did not show any significant clinical distinction in the outcome assessments. Pulling out an impacted canine by orthodontic methods entails appropriate force magnitude and correct direction of application. In rare conditions, the severity of the complication can demand either autotransplantation or surgical removing of the impacted canine. 

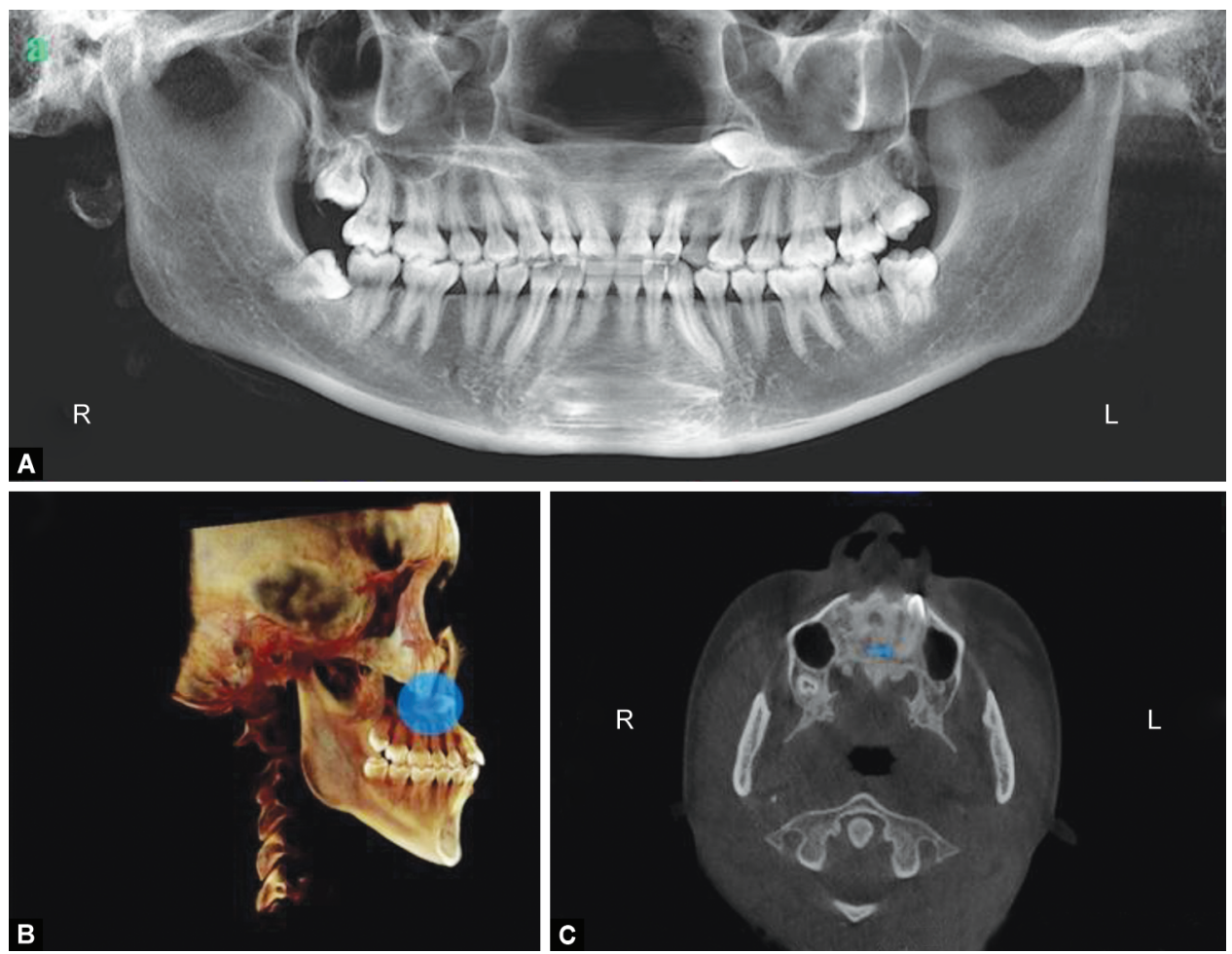

Figs 5 A to C: A case indicated for surgical removal due to deep impaction as visualized in oral pantograph (A) and also long bulgy root appearance in 3D volumetric reconstruction (B). Take note of the blue arrow pointing the medial dilaceration of the apex, which was apparent only in axial slice from the inferior occlusal view (C)

\section{Clinical Significance}

The impaction of maxillary canines is one of the most frequent reasons for orthodontic referrals. Although most of the cases are managed with combination of surgical-orthodontic techniques, a differential diagnosis and a thorough clinical evaluation are required to choose the best approach. The diagnosis of such condition is a multifactorial process, which depends on patient age, tooth development level, geometrical variables and impaction severity, possible etiological elements, nearby anatomical structures and adjacent roots, and last but not least patient motivation level to seek a particular treatment option. Considering the upper canines as one the key factors in smile designing and occlusion, proper management of this condition should not be avoided in clinical orthodontics. Aside from that, it is a must to inform and explain to the patient before formulating any treatment plan. To achieve the latter, being updated about the current techniques and their outcomes are of great importance for practitioners.

\section{References}

1. Kim Y, Hyun H, Jang K. Interrelationship between the position of impacted maxillary canines and the morphology of the maxilla. Am J Orthod Dentofac Orthop 2012;141(5):556-562. DOI: 10.1016/ j.ajodo.2011.11.015.

2. Litsas G. A review of early displaced maxillary canines: etiology, diagnosis and interceptive treatment. Open Dent J 2011;5(1):39-47. DOI: $10.2174 / 1874210601105010039$.

3. Mucedero M, Ricchiuti MR, Cozza P, et al. Prevalence rate and dentoskeletal features associated with buccally displaced maxillary canines. Eur J Orthod 2013;35(3):305-309. DOI: 10.1093/ejo/cjr133.

4. Bedoya MM, Park JH. A review of the diagnosis and management of impacted maxillary canines. J Am Dent Assoc 2009;140(12):1485-1493. DOI: 10.14219/jada.archive.2009.0099.
5. Yan B, Sun Z, Fields $H$, et al. Etiologic factors for buccal and palatal maxillary canine impaction: a perspective based on cone-beam computed tomography analyses. Am J Orthod Dentofac Orthop 2013;143(4):527-534. DOI: 10.1016/j.ajodo.2012.11.021.

6. Becker A, Chaushu S. Etiology of maxillary canine impaction: a review. Am J Orthod Dentofac Orthop 2015;148(4):557-567. DOI: 10.1016/ j.ajodo.2015.06.013.

7. Fleming PS. Multi-disciplinary management to align ectopic or impacted teeth. Semin Orthod 2015;21(1):38-45. DOI: 10.1053/ j.sodo.2014.12.004.

8. Becker A, Chaushu G, Chaushu S. Analysis of failure in the treatment of impacted maxillary canines. Am J Orthod Dentofac Orthop 2010;137(6):743-754. DOI: 10.1016/j.ajodo.2008.07.022.

9. Alqerban A, Storms A-S, Voet M, et al. Early prediction of maxillary canine impaction. Dentomaxillofacial Radiol 2016;45(3):20150232. DOI: 10.1259/dmfr.20150232.

10. Warford JH, Grandhi RK, Tira DE. Prediction of maxillary canine impaction using sectors and angular measurement. Am J Orthod Dentofac Orthop 2003;124(6):651-655. DOI: 10.1016/S08895406(03)00621-8.

11. Alqerban A, Jacobs R, Fieuws $S$, et al. Radiographic predictors for maxillary canine impaction. Am J Orthod Dentofacial Orthop 2015;147(3):345-354. DOI: 10.1016/j.ajodo.2014.11.018.

12. Sajnani AK. Permanent maxillary canines - review of eruption pattern and local etiological factors leading to impaction. J Investig Clin Dent 2015;6(1):1-7. DOI: 10.1111/jicd.12067.

13. Doğramacı EJ, Naini FB. Impacted maxillary canines: contemporary management and review of the literature. Fac Dent J 2012;3(4): 210-217. DOI: $10.1308 / 204268512 X 13466824724715$.

14. Husain J, Burden D, McSherry $P$, et al. National clinical guidelines for management of the palatally ectopic maxillary canine. Br Dent $J$ 2012;213(4):171-176. DOI: 10.1038/sj.bdj.2012.726.

15. Alyammahi AS, Kaklamanos EG, Athanasiou AE. Effectiveness of extraction of primary canines for interceptive management of palatally displaced permanent canines: a systematic review and 
meta-analysis. Eur J Orthod 2018;40(2):149-156. DOI: 10.1093/ejo/ cjx042.

16. Naoumova J, Kurol J, Kjellberg H. Extraction of the deciduous canine as an interceptive treatment in children with palatal displaced canines - part I: shall we extract the deciduous canine or not? Eur J Orthod 2014;37(2):209-218. DOI: 10.1093/ejo/cju040.

17. O'Neill J. Limited evidence for interceptive extraction of deciduous teeth to prevent permanent canine impaction. Evid Based Dent 2013;14(1):23-24. DOI: 10.1038/sj.ebd.6400918.

18. Ericson S, Kurol J. Radiographlc assessment of maxillary canine eruption in children with clinical signs of eruption disturbance. Eur J Orthod 1986;8(3):133-140. DOI: 10.1093/ejo/8.3.133.

19. Ericson S, Kurol J. Early treatment of palatally erupting maxillary canines by extraction of the primary canines. Eur J Orthod 1988;10(4):283-295. DOI: 10.1093/ejo/10.4.283.

20. Sajnani AK, King NM. Retrospective audit of management techniques for treating impacted maxillary canines in children and adolescents over a 27-year period. J Oral Maxillofac Surg 2011;69(10):2494-2499. DOI: 10.1016/j.joms.2011.05.018.

21. Leonardi M, Armi P, Franchi L, et al. Two interceptive approaches to palatally displaced canines: a prospective longitudinal study. Angle Orthod 2004;74(5):581-586. DOI: 10.1043/0003-3219(2004)074<0581:TIATPD>2.0.CO;2.

22. Vilarinho MA, de Lira ALS. Palatally impacted canine: diagnosis and treatment options. Braz J Oral Sci 2010;9(2):70-76.

23. Naoumova J, Kürol J, Kjellberg H. Extraction of the deciduous canine as an interceptive treatment in children with palatally displaced canines-part II: possible predictors of success and cut-off points for a spontaneous eruption. Eur J Orthod 2015;37(2):219-229. DOI: 10.1093/ejo/cju102.

24. Naoumova J, Kurol J, Kjellberg H. A systematic review of the interceptive treatment of palatally displaced maxillary canines. Eur J Orthod 2011;33(2):143-149. DOI:10.1093/ejo/cjq045.

25. Armi P, Cozza P, Baccetti T. Effect of RME and headgear treatment on the eruption of palatally displaced canines: a randomized clinical study. Angle Orthod 2011;81(3):370-374. DOI: 10.2319/062210339.1.

26. Baccetti T. Risk indicators and interceptive treatment alternatives for palatally displaced canines. Semin Orthod 2010;16(3):186-192. DOI: 10.1053/j.sodo.2010.05.004.

27. Sigler LM, Baccetti T, McNamara JA. Effect of rapid maxillary expansion and transpalatal arch treatment associated with deciduous canine extraction on the eruption of palatally displaced canines: a 2-center prospective study. Am J Orthod Dentofac Orthop 2011;139(3): e235-e244. DOI: 10.1016/j.ajodo.2009.07.015.

28. Bazargani F, Magnuson A, Lennartsson B. Effect of interceptive extraction of deciduous canine on palatally displaced maxillary canine: a prospective randomized controlled study. Angle Orthod 2014;84(1):3-10. DOI: 10.2319/031013-205.1.

29. Hadler-Olsen S, Pirttiniemi P, Kerosuo H, et al. Does headgear treatment in young children affect the maxillary canine eruption path? Eur J Orthod 2018;40(6):583-591. DOI: 10.1093/ejo/cjy013.

30. Becker A, Chaushu S. Surgical treatment of impacted canines. Oral Maxillofac Surg Clin North Am 2015;27(3):449-458. DOI: 10.1016/ j.coms.2015.04.007.

31. Kokich VG. Preorthodontic uncovering and autonomous eruption of palatally impacted maxillary canines. Semin Orthod 2010;16(3): 205-211. DOI: 10.1053/j.sodo.2010.05.008.

32. Becker A, Zogakis I, Luchian I, et al. Surgical exposure of impacted canines: open or closed surgery? Semin Orthod 2016;22(1):27-33. DOI: 10.1053/j.sodo.2015.10.005.

33. Suri S, Utreja A, Rattan V. Orthodontic treatment of bilaterally impacted maxillary canines in an adult. Am J Orthod Dentofac Orthop 2002;122(4):429-437. DOI: 10.1067/mod.2002.126406.

34. Becker A, Abramovitz I, Chaushu S. Failure of treatment of impacted canines associated with invasive cervical root resorption. Angle Orthod 2013;83(5):870-876. DOI: 10.2319/090812-716.1.
35. Vanarsdall RL. Efficient management of unerupted teeth: a timetested treatment modality. Semin Orthod 2010;16(3):212-221. DOI: 10.1053/j.sodo.2010.05.009.

36. Kohavi D, Becker A, Zilberman Y. Surgical exposure, orthodontic movement, and final tooth position as factors in periodontal breakdown of treated palatally impacted canines. Am J Orthod 1984;85(1):72-77. DOI: 10.1016/0002-9416(84)90124-6.

37. Torres-Lagares D, Hita-Iglesias $P, A z c a ́ r a t e-V e l a ́ z q u e z ~ F$, et al. What are the histologic effects of surgical and orthodontic treatment on the gingiva of palatal impacted canines? J Oral Maxillofac Surg 2015;73(12):2273-2281. DOI: 10.1016/j.joms.2015.07.002.

38. Kössger H, Polat HB, Demirer $\mathrm{S}$, et al. Periodontal healing of marginal flap versus paramarginal flap in palatally impacted canine surgery: a prospective study. J Oral Maxillofac Surg 2009;67(9):1826-1831. DOI: 10.1016/j.joms.2009.04.023.

39. Crescini A, Nieri M, Buti J, et al. Pre-treatment radiographic features for the periodontal prognosis of treated impacted canines. J Clin Periodontol 2007;34(7):581-587. DOI: 10.1111/j.1600051X.2007.01094.X.

40. Stivaros N, Mandall NA. Radiographic factors affecting the management of impacted upper permanent canines. J Orthod 2000;27(2):169-173. DOI: 10.1093/ortho/27.2.169.

41. Pitt S, Hamdan A, Rock P. A treatment difficulty index for unerupted maxillary canines. Eur J Orthod 2006;28(2):141-144. DOI: 10.1093/ejo/ cji068.

42. Becker A, Chaushu S. Success rate and duration of orthodontic treatment for adult patients with palatally impacted maxillary canines. Am J Orthod Dentofac Orthop 2003;124(5):509-514. DOI: 10.1016/S0889-5406(03)00578-X.

43. Spuntarelli M. Combined orthodontic-surgical approach in the treatment of impacted maxillary canines: three clinical cases. Oral Implantol 2015;8(2-3):63-67. DOI: 10.11138/orl/2015.8.2.063.

44. Huang $Y-S$, Lin $Y-C$, Hung $C-Y$, et al. Surgical considerations and management of bilateral labially impacted canines. J Dent Sci 2016;11(2):202-206. DOI: 10.1016/j.jds.2013.02.027.

45. Kaczor-Urbanowicz K, Zadurska M, Czochrowska E. Impacted teeth: an interdisciplinary perspective. Adv Clin Exp Med 2016;25(3): 575-585. DOI: 10.17219/acem/37451.

46. Becker A. Extreme tooth impaction and its resolution. Semin Orthod. 2010;16(3):222-233. DOI: 10.1053/j.sodo.2010.05.010.

47. Parkin NA, Milner RS, Deery C, et al. Periodontal health of palatally displaced canines treated with open or closed surgical technique: a multicenter, randomized controlled trial. Am J Orthod Dentofac Orthop 2013;144(2):176-184. DOI: 10.1016/j.ajodo.2013.03.016.

48. Lee JY, Choi YJ, Choi S, et al. Labially impacted maxillary canines after the closed eruption technique and orthodontic traction: a split-mouth comparison of periodontal recession. J Periodontol 2019;90(1):35-43. DOI: 10.1002/JPER.18-0034.

49. Crescini A, Clauser C, Giorgetti R, et al. Tunnel traction of infraosseous impacted maxillary canines. A three-year periodontal follow-up. Am J Orthod Dentofac Orthop 1994;105(1):61-72. DOI: 10.1016/S08895406(94)70100-8.

50. FischerTJ. Orthodontic treatment acceleration with corticotomy-assisted exposure of palatally impacted canines. Angle Orthod 2007;77(3): 417-420. DOI: 10.2319/0003-3219(2007)077[0417:OTAWCE]2. $0 . \mathrm{CO} ; 2$.

51. Ferguson DJ, Al Rossais D, Wilcko MT, et al. Forced-eruption time for palatally impacted canines treated with and without ostectomydecortication technique. Angle Orthod 2019;89(5):697-704. DOI: 10.2319/111418-809.1.

52. Viwattanatipa $\mathrm{N}$, Charnchairerk S. The effectiveness of corticotomy and piezocision on canine retraction: a systematic review. Korean J Orthod 2018;48(3):200-211. DOI: 10.4041/kjod.2018.48.3.200.

53. Sampaziotis D, Tsolakis IA, Bitsanis E, et al. Open versus closed surgical exposure of palatally impacted maxillary canines: comparison of the different treatment outcomes-a systematic review. Eur J Orthod 2018;40(1):11-22. DOI: 10.1093/ejo/cjw077. 
54. Cassina C, Papageorgiou SN, Eliades T. Open versus closed surgical exposure for permanent impacted canines: a systematic review and meta-analyses. Eur J Orthod 2018;40(1):1-10. DOI: 10.1093/ejo/cjx047.

55. Mummolo S, Nota A, De Felice ME, et al. Periodontal status of buccally and palatally impacted maxillary canines after surgical-orthodontic treatment with open technique. J Oral Sci 2018;60(4):552-556. DOI: 10.2334/josnusd.17-0394.

56. Incerti-Parenti S, Checchi V, Ippolito DR, et al. Periodontal status after surgical-orthodontic treatment of labially impacted canines with different surgical techniques: a systematic review. Am J Orthod Dentofac Orthop 2016;149(4):463-472. DOI: 10.1016/j.ajodo.2015. 10.019 .

57. Parkin NA, Freeman JV, Deery C, et al. Esthetic judgments of palatally displaced canines 3 months postdebond after surgical exposure with either a closed or an open technique. Am J Orthod Dentofac Orthop 2015;147(2):173-181. DOI: 10.1016/j.ajodo.2014.10.026.

58. Sherwood K. Evidence-based surgical-orthodontic management of impacted teeth. Atlas Oral Maxillofac Surg Clin 2013;21(2):199-210. DOI: 10.1016/j.cxom.2013.05.006.

59. Garcovich D, Aiuto R, Lozano Serrano E, et al. Uncovering and autonomous eruption of palatally impacted canines. Eur J Paediatr Dent 2018;19(4):300-302. DOI: 10.23804/ejpd.2018.19.04.9.

60. Mathews DP, Kokich VG. Palatally impacted canines: the case for preorthodontic uncovering and autonomous eruption. Am J Orthod Dentofac Orthop 2013;143(4):450-458. DOI: 10.1016/j.ajodo.2013.02.011.

61. Cruz RM. Orthodontic traction of impacted canines: concepts and clinical application. Dental Press J Orthod 2019;24(1):74-87. DOI: 10.1590/2177-6709.24.1.074-087.bbo.

62. Heravi F, Shafaee H, Forouzanfar A, et al. The effect of canine disimpaction performed with temporary anchorage devices (TADs) before comprehensive orthodontic treatment to avoid root resorption of adjacent teeth. Dental Press J Orthod 2016;21(2):65-72. DOI: 10.1590/2177-6709.21.2.065-072.oar.

63. Kocsis A, Seres L, Kocsis-Savanya G, et al. [Skeletal anchorage: use of miniscrews for impacted maxillary canine management]. Fogorv $\mathrm{Sz}$ 2010;103(1):3-9.

64. Singh K, Reddy CM, Joshi D, et al. Treatment of maxillary impacted canine using ballista spring and orthodontic wire traction. Marwah N, editor. Int J Clin Pediatr Dent 2017;10(3):313-317. DOI: 10.5005/ jp-journals-10005-1457.
65. Nakandakari C, Gonçalves JR, Cassano DS, et al. Orthodontic traction of impacted canine using cantilever. Case Rep Dent 2016;2016:4386464. DOI: 10.1155/2016/4386464.

66. Schubert M. The alignment of impacted and ectopic teeth using the Easy-Way-Coil (EWC ${ }^{\circledR}$ ) system. J Orofac Orthop 2008;69(3):213-226. DOI: 10.1007/s00056-008-0722-9.

67. Schubert M, Proff P, Kirschneck C. Successful treatment of multiple bilateral impactions - a case report. Head Face Med 2016;12(1):24. DOI: 10.1186/s13005-016-0122-0.

68. Shastri D, Nagar A, Tandon P. Alignment of palatally impacted canine with open window technique and modified K-9 spring. Contemp Clin Dent 2014;5(2):272-274. DOI: 10.4103/0976-237X.132362.

69. Kim SH, Choo M, Hwang D, et al. Double-archwire mechanics using temporary anchorage devices to relocate ectopically impacted maxillary canines. World J Orthod 2008;9(3):255-266.

70. StrbacGD, Giannis K, MittlböckM, etal.Survival rate of autotransplanted teeth after 5 years - a retrospective cohort study. J Craniomaxillofac Surg 2017;45(8):1143-1149. DOI: 10.1016/j.jcms.2017.03.023.

71. Grisar K, Chaabouni D, Romero LPG, et al. Autogenous transalveolar transplantation of maxillary canines: a systematic review and meta-analysis. Eur J Orthod 2018;40(6):608-616. DOI: 10.1093/ejo/ cjy026.

72. Kokai S, Kanno Z, Koike S, et al. Retrospective study of 100 autotransplanted teeth with complete root formation and subsequent orthodontic treatment. Am J Orthod Dentofac Orthop 2015;148(6):982-989. DOI: 10.1016/j.ajodo.2015.06.018.

73. Machado LA, do Nascimento RR, Ferreira DMTP, et al. Long-term prognosis of tooth autotransplantation: a systematic review and meta-analysis. Int J Oral Maxillofac Surg 2016;45(5):610-617. DOI: 10.1016/j.ijom.2015.11.010

74. Cardaropoli D, Debernardi GC. Immediate placement of implant into impacted maxillary canine extraction socket. Int J Periodontics Restor Dent 2007;27(1):71-77.

75. García B, Boronat A, Larrazabal C, et al. Immediate implants after the removal of maxillary impacted canines: a clinical series of nine patients. Int J Oral Maxillofac Implants 2009;24(2):348-352.

76. Zuiderveld EG, Meijer HJA, Vissink A, et al. Immediate placement and provisionalization of an implant after removal of an impacted maxillary canine: two case reports. Int J Implant Dent 2015;1(1):13. DOI: 10.1186/s40729-015-0013-3. 